\title{
A Configurable Multi-Sensor Tripod For the Study of Near-Bottom Ocean Processes
}

\author{
R. Birch ${ }^{1}$, P. R. Hill ${ }^{2}$, M. Clarke ${ }^{1}$, D. Lemon ${ }^{1}, \&$ D. Fissel ${ }^{1}$
}

\author{
${ }^{1}$ ASL Environmental Sciences, \\ 1986 Mills Road, \\ North Saanich, BC, Canada, V8L 5Y3 \\ asl@aslenv.com
}

\begin{abstract}
A cost effective and highly configurable scientific platform, dubbed Norton, has been developed for the scientific study of near-bottom ocean processes. The basic platform is a collapsible lightweight aluminum tripod that can be transported in the back of a pick-up truck, and is easily accommodated on most vessels. Ballast is supplied in the form of large ship anodes bolted to the base of each leg. The desired sensors are attached to the tripod legs and bracing. A typical deployment might utilize the following sensors:

- Acoustic Doppler Current Profiler for current profiles and directional wave data.

- Marsh McBirney electromagnetic flow sensor for measurements close to the bottom, supporting both wave orbital burst sampling and average current measurements.

- Optical Backscatter sensors (OBS) for sediment concentration.

- Sector-scanning sonar to supply bed-form images; an Imagenex variable frequency scanning head has been integrated into a self-contained housing containing a control module, data logger and power supply.

Other sensors can be added as desired. Norton is usually deployed by lowering with a line from the ship. An acoustic release is used to let go of the tripod once it is on bottom. A customized 'tilt-pinger' provides confirmation to the crew that the tripod is upright. Recovery can be via a pop-up buoy and/or a ground-line.
\end{abstract}

\section{INTRODUCTION}

As part of the Georgia Basin Geohazards Initiative, the Geological Survey of Canada is studying erosion and sediment transport on the Fraser River delta. The Geological Survey of Canada has had considerable success on Canada's east coast using a platform termed Ralph [1], [2]. When a similar requirement for sediment transport measurements on the Fraser River delta became necessary, ASL was contacted to build a suitable instrument platform.

While its origins are obscure, there seems to be a trend in naming bottom tripod/frames after characters from the old Honeymooners TV series. The New Zealand National Institute of Water \& Atmospheric Research called theirs Alice, after the lead female character, and as mentioned, the Geological Survey of Canada on the east coast named theirs Ralph, after the lead male role. The Ralph platform is

\author{
${ }^{2}$ Natural Resources Canada, \\ Geological Survey of Canada, \\ P.O. Box 6000, Sidney, BC, Canada, V8L 4B2 \\ phill@NRCan.gc.ca \\ GSC Publication No. 2003086
}

quite big and burly, much like the actor Jackie Gleason who played that role. When the Canadian west coast version was built, it was more lightweight and mobile, and we named it Norton after Ralph's scrawny and somewhat idiosyncratic sidekick. Characteristically, Norton's aluminum legs buckled slightly during the latest recovery, after encountering a much larger mass (the recovery vessel).

\section{NORTON TRIPOD CONFIGURATION}

\section{A. The Tripod}

The Norton platform is an aluminum tripod with a base dimension of about $3 \mathrm{~m}$ and an overall height of $2.2 \mathrm{~m}$. Aluminum was chosen for its light weight and resistance to corrosion. Large ship anodes are added to the base of the legs for stability as well as corrosion protection. A midsection brace adds strength as well as a means of attaching instruments. The legs are hinged and with the mid-section removed they collapse, making the platform easily transportable (it fits in the back of a pickup truck).

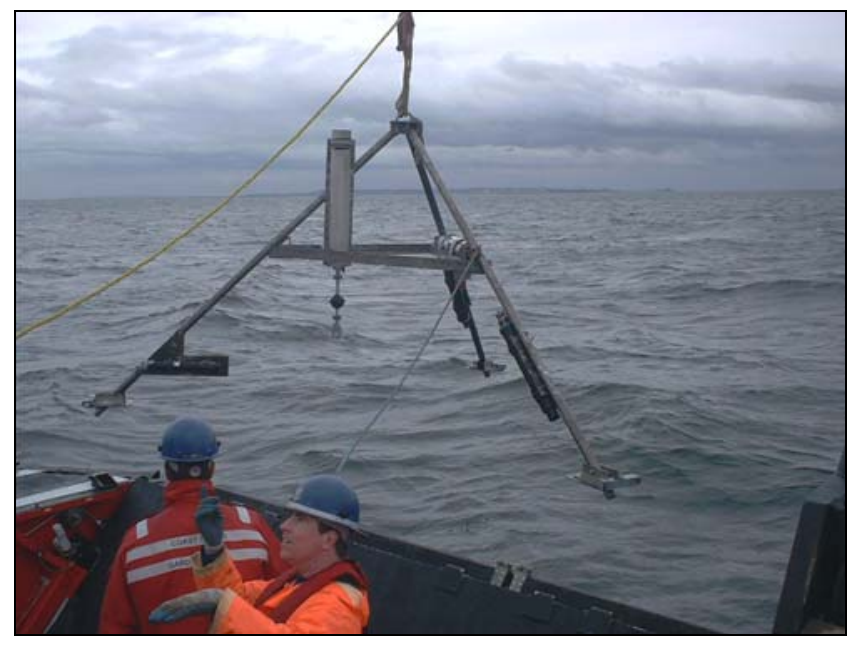

Fig.1. Norton being recovered from its inaugural deployment off the Fraser River delta.

B. Sensor Suite 
Norton is easily configurable with whatever sensors are required. Instruments such as OBS sensors and Doppler current profilers are generally attached to the tripod legs whereas the scanning sonar and electromagnetic flow sensors are normally mounted in the open area directly under the tripod.

At present the instruments are stand-alone with each having its own power supply and data logger. Time synchronization is used to later merge the data streams. This approach provides a highly configurable suite of various sensors that can be optimized for a particular application, and it also ensures simple field assembly and operation.

Instruments that have been used on Norton to date include:

- Coastal Leasing MiniSpec current/wave gauge. This instrument is equipped with a Marsh McBirney flow sensor for measuring near-bottom currents, and in burst mode measures the wave orbital velocities. It also has a Paroscientific pressure sensor for wave height measurements. When combined with the orbital velocity data, wave directions can also be determined (PUV method).

- Imagenex 881A Scanning Sonar. The multi-frequency $(175-1000 \mathrm{kHz})$ scanning sonar head was integrated to a custom-built data logger/power supply. A large alkaline battery pack and up to $1 \mathrm{~GB}$ of data storage, allow the instrument to be deployed for 8-10 months using an hourly scan rate.

- OBS Sensors. Norton is usually outfitted with two D\&A Optical Back Scatter (OBS) sensors, at different heights above bottom. The OBS sensors are standalone using an Applied Microsystems CTD platform for power and data logging. Sediment samples are usually collected from the site to allow post-survey conversion of the OBS sensors output to suspended sediment concentration units.

- $\quad$ Acoustic Doppler Profiler. Doppler current profilers can be added to provide current profile data, as well as (directional) wave data.

\section{Deployment / Recovery}

To date Norton has been deployed twice off the Fraser River delta, once in $10 \mathrm{~m}$ water depth, and most recently on a tidal bank that dries at low tide. On both occasions, the Canadian Coast Guard Hovercraft Siyay was used for deployment and recovery. At the $10 \mathrm{~m}$ depth site, the tripod was deployed with a ground-line and an acoustic release-activated pop-up buoy at the end of the ground-line. During recovery the pop-up buoy failed to surface and the ground line was snagged with a grapple. In the oceanographic community there is often some doubt as to whether a bottom frame is upright after deployment. ASL has developed a tilt-pinger that pings only if it is within $20^{\circ}$ of vertical, providing assurance that the tripod was deployed upright.
On the tidal bank, the deployment was relatively easy. The hovercraft settled onto the sand bank at low tide and the crane was used to swing the tripod over the side. The field team then disembarked to measure the tripod heading, collect sediment samples, take photographs, and measure the bedforms. When the tripod was recovered a month later, the tide was higher but the top of the tripod was above water and easily recovered.

\section{TWO DEPLOYMENTS ON ROBERTS BANK, THE FRASER RIVER DELTA}

\section{A. Environment, Background Oceanography}

The Strait of Georgia separates Vancouver Island from the BC mainland. The Fraser River enters the ocean at Vancouver and many of its suburbs are located on the subaerial delta. The main channel is dredged and the Steveston Jetty was built along the northern portion of the channel extending $5 \mathrm{~km}$ into the Strait. This and other river management projects have deprived some areas of the delta front of much of the sediment formerly received during the peak spring discharge.

Tides within the Strait are mixed, mainly semi-diurnal, with ranges up to about 3-5 m. Tidal current speeds can exceed $1 \mathrm{~m} \mathrm{~s}^{-1}$. The Strait has limited fetch for wave generation with the largest waves affecting the delta coming from the west-northwest (approximately $80 \mathrm{~km}$ fetch in this direction). Wave heights are generally less than 0.5-1 $\mathrm{m}$ [3]. Significant waves heights up to about $3.4 \mathrm{~m}$ height, and about 7.5 second period, have been recorded in the deeper water off the delta (Fisheries and Oceans Canada station \#108; http://www.meds-sdmm.dfompo.gc.ca/meds/Databases/Wave/).

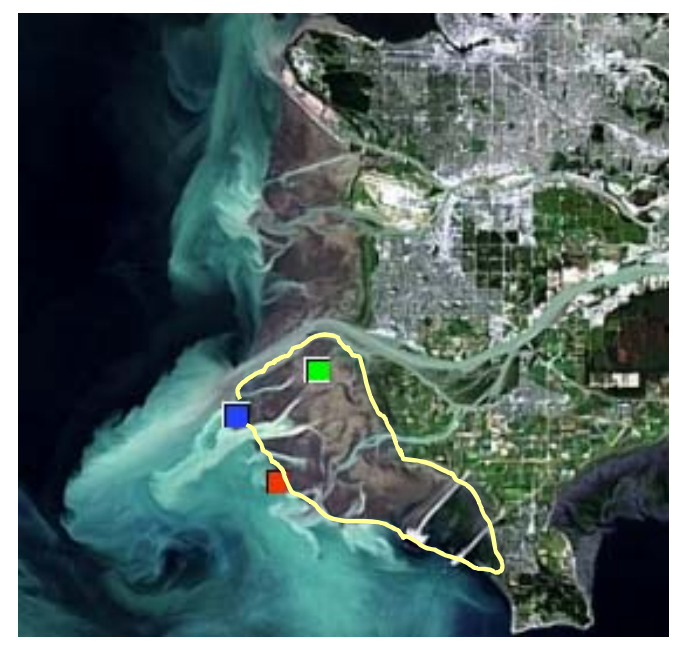

Fig. 2. 2001 Landsat image of the Fraser River delta showing the 2002 site ( $=$ =Norton) in $10 \mathrm{~m}$ water depth, and the 2003 locations in $8 \mathrm{~m}(\boldsymbol{\square}=\mathrm{ADCP})$ and $0 \mathrm{~m}$ ( $\square=$ Norton $)$ depths. Roberts Bank is outlined in yellow. 
Roberts Bank is located just south of where the main (South Arm) Fraser River channel enters the Strait of Georgia. The substrate of Roberts Bank is primarily sand with a mean grain size of about $0.125 \mathrm{~mm}$ [4]. The sand becomes finer-grained towards the shore.

It is generally thought that much of the slope of Roberts Bank is being eroded, with the possible exception of the northern portion of the Bank. There is evidence for sand from the South Arm becoming incorporated in a clockwise gyre across the north half of Roberts Bank [5]. Numerical model results indicate the formation of a clockwise eddy on the Bank during weak flood tides, apparently caused by the Steveston Jetty [6]. The Steveston Jetty provides partial protection from winter storm waves from the westnorthwest. The dominant tidal currents and breaking waves can generate a net longshore current over Roberts Bank [7].

\section{B. Winter 2002 Deployment on Roberts Bank}

The Norton tripod was deployed in $10 \mathrm{~m}$ water depth off the edge of Roberts Bank ( $\square$ in Fig. 2 above). Previous multibeam surveys show outcropping beds aligned roughly north-south in the $5-15 \mathrm{~m}$ depth range, indicative of net erosion [8]. Further offshore (20-30 m depths) were subaqeous dunes aligned northeast-southwest, perpendicular to the predominant direction of tidal flow.

The currents were tidally dominated with flood tides (northerly) stronger than ebb, up to $1 \mathrm{~m} / \mathrm{s}$ versus $0.4 \mathrm{~m} \mathrm{~s}^{-1}$ respectively. The peak tidal flows re-suspended bottom sediment on both the flood and ebb.

Several storm events were recorded with significant wave heights up to $1 \mathrm{~m}$, and 5 second peak periods. The scanning sonar (set to $30 \mathrm{~m}$ range and default gain and frequency settings) showed high suspended sediment concentrations just trailing the storms and the emergence of long wavelength (c. $10 \mathrm{~m})$, low-relief, irregular patches [8].

\section{Preliminary Results from the Winter 2003 Deployment on Roberts Bank}

The 2003 deployment of Norton was at a location on Roberts Bank where bedforms were expected to consist of small ripple features about $2 \mathrm{~cm}$ high with a $5-10 \mathrm{~cm}$ wavelength. The Imagenex scanning sonar settings were optimized for this deployment using tank tests.

A series of three ripples were created in the laboratory using fine-grained sand to simulate the expected bedforms on the Bank. Frequency and gain settings were then varied until optimal sonar images were obtained (Fig. 3). Echo returns at approximately $1.6 \mathrm{~m}$ range are from the tank wall. The final settings chosen were: $1 \mathrm{MHz}$ frequency, 5 $\mathrm{m}$ range, and $18 \mathrm{~dB}$ gain.
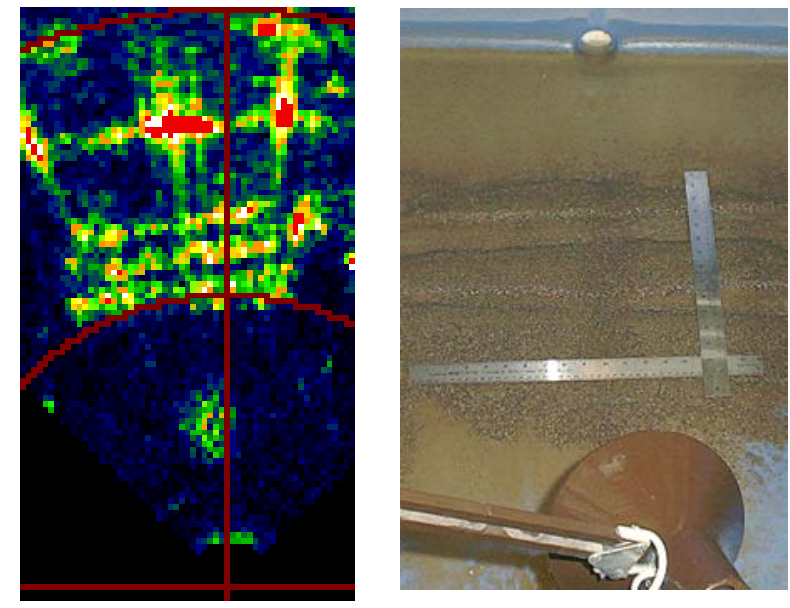

Fig. 3. Imagenex sonar image (left) of test ripples (about 1$2 \mathrm{~cm}$ height, about $10 \mathrm{~cm}$ length) in tank. Red range rings are $1 \mathrm{~m}$ increments. Three sand ripples are shown starting at $1 \mathrm{~m}$ range (first red ring).

The Norton tripod was deployed on Roberts Bank ( $\square$ in Fig. 2) at low tide (Fig. 4 below).

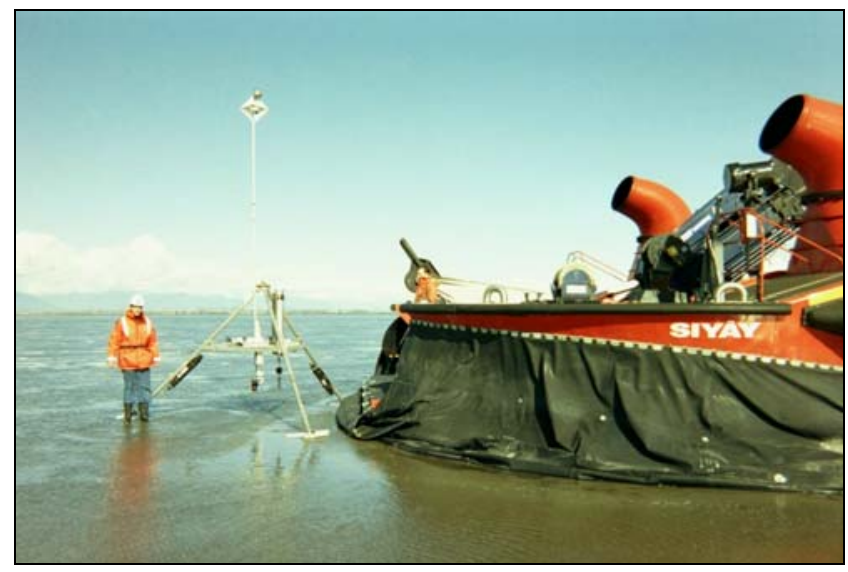

Fig. 4. Deployment of Norton on Roberts Bank March 23, 2003 using the Canadian Coast Guard Hovercraft Siyay. A radar reflector and flashing light were mounted on a pole above the tripod.

A $1200 \mathrm{kHz}$ RD Instruments WH ADCPTM with Waves firmware was deployed in $9 \mathrm{~m}$ water depth just offshore of the edge of the Bank ( $\square$ in Fig. 2). The ADCP was to measure the 'offshore' waves so that we could determine the wave attenuation over the Bank. During the deployment, winds were blowing from the northwest and waves about $1 \mathrm{~m}$ high could clearly be seen breaking on the edge of the bank, reducing in height as they moved onto the Bank.

Using the settings previously determined in the laboratory, the Imagenex scanning sonar head was suspended from the tripod at a height of $45 \mathrm{~cm}$ above bottom. 
At the time of deployment (Fig. 5 below) the bedforms consisted of sand ripples about 1-2 cm high, and about 5-10 $\mathrm{cm}$ wavelength, similar to the ones fabricated in the test tank. The ripples were not continuous, nor linear, and far more complicated than the ones created for the tank test.

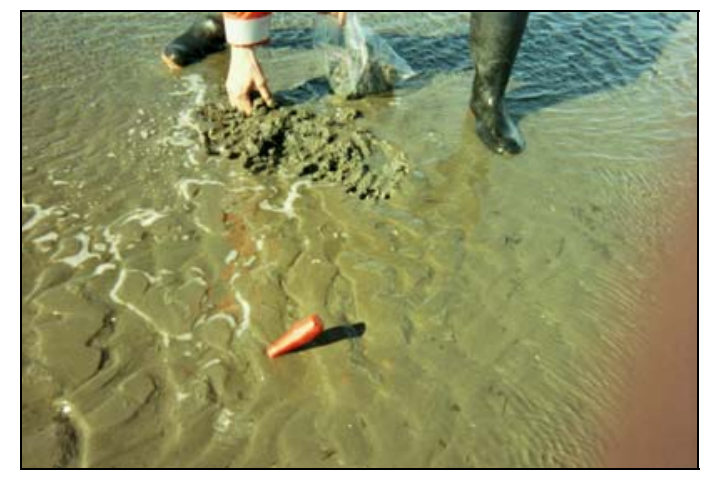

Fig. 5. Bedforms at time of deployment: ripples about $1 \mathrm{~cm}$ high, with about $7 \mathrm{~cm}$ wavelength. Overall trend in ripples was approximately northeast-southwest.

The first images from the scanning sonar (after the tide had risen enough to submerge the instrument) show ripple-like features, particularly in the northwest quadrant with wavelengths of the same magnitude as seen visually (Fig. 6). The ripple features are oriented northeast-southwest. The reversed-grey color option best shows the ripple features.

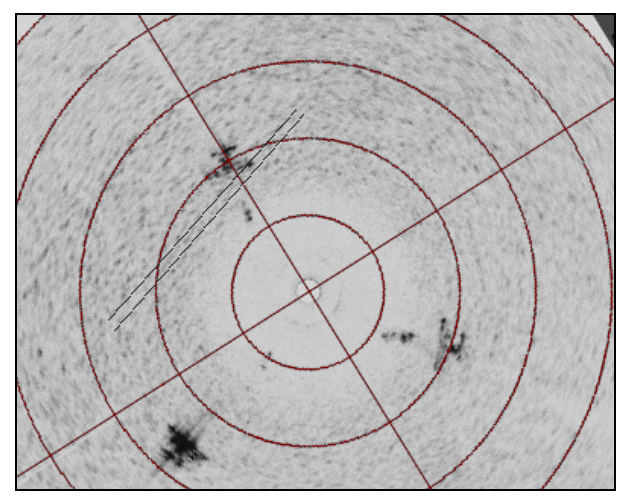

Fig. 6. First image (image 03231900) from the scanning sonar after the tide had submerged the sonar head. Tripod legs and instruments show up darkest, with ripple-like features evident, particularly in the northwest quadrant. Parallel lines are used to highlight ripple features having a NE-SW orientation.

Ripple-like features were occasionally evident on sonar images at other times, but their characteristics (wavelength, orientation, etc) did not vary significantly from those observed initially. Several 'storms' occurred during the deployment, but significant wave heights in the deepwater increased to only about $1 \mathrm{~m}$, and the sonar images following the storms were not noticeably different than before.
The scanning sonar often recorded radial patterns, with a generally low reflectivity background (Fig. 7 below). These images occurred frequently and nearly always during a lower high tide (consecutive high tides are different heights due to the diurnal inequality), and not when successive low tides were of similar height (more purely semi-diurnal tide). OBS levels ( $0.3 \mathrm{~m}$ off bottom) were low at these times (about 10 FTU, up to 20-30 max). Currents were generally weak with speeds of about $20 \mathrm{~cm} \mathrm{~s}^{-1}$.

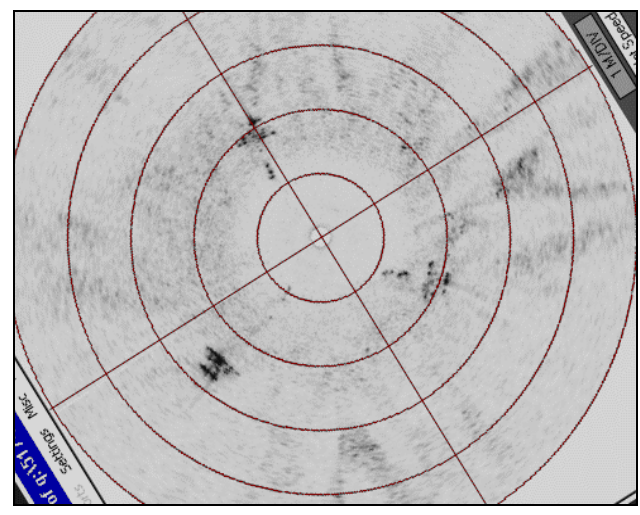

Fig. 7. Radial-pattern sonar image (image 040909).

Another interesting occurrence was high suspended sediment concentrations at diurnal time scales, centered on the lower low tides. Sonar images such as the one below were recorded just prior to, and immediately following, the emergence of the sonar head from the water as the tide was falling.

The suspended sediment signal from the OBS sensor $30 \mathrm{~cm}$ above bottom clearly shows the diurnal nature of the signal (Fig. 9 below). The 'dropouts' in the middle of the peaks are when the sensor was in air at low tide. Waves from the west added to the high OBS readings on the $21^{\text {st }}$.

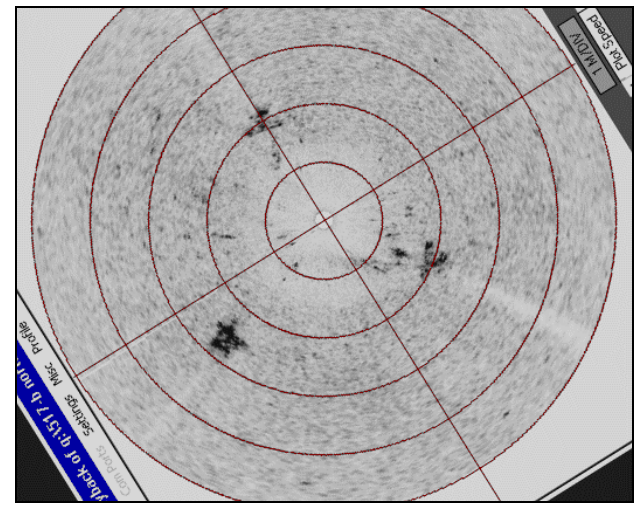

Fig. 8. High suspended sediment concentration during moderate westerly winds and near low tide (image 04051200). 


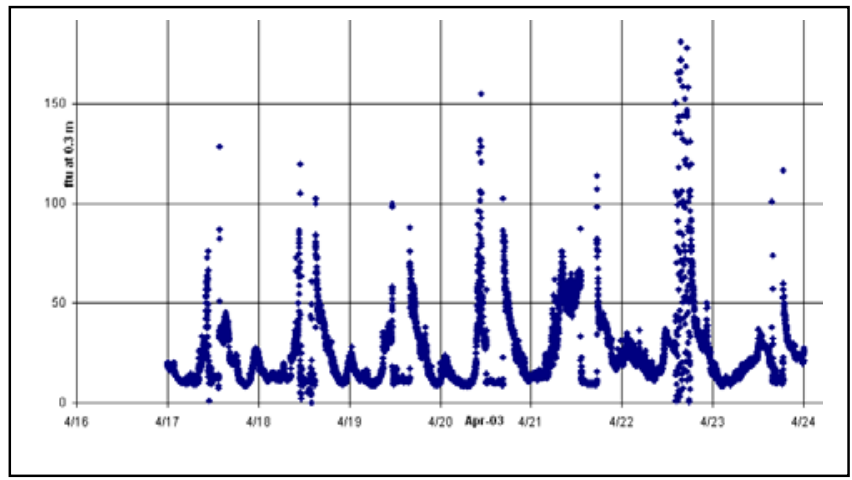

Fig. 9. Uncorrected OBS readings from the sensor $30 \mathrm{~cm}$ off bottom, showing high suspended sediment concentrations at lower low water.

These OBS diurnal peaks occurred only during the lowest low tides, the lower low tides that occurred when the diurnal inequality was most pronounced. Lower low tides are accompanied by strong ebb and flood currents, up to 50 $\mathrm{cm} \mathrm{s}^{-1}$ ebb and $125 \mathrm{~cm} \mathrm{~s}^{-1}$ flood, as recorded by the ADCP located in 8-10 $\mathrm{m}$ water depth off the edge of the Bank (Fig. 10). Note that the flood tide associated with the preceding higher low tide is negligible.
Data from the Norton sensors help explain the processes causing these high suspended sediment values (Fig. 11). Starting at high tide, suspended sediment values are low and currents weak (near slack). As the tide ebbs and the water level drops, the current speed increases to $40-50 \mathrm{~cm}$ $\mathrm{s}^{-1}$, and suspended sediment levels increase. As low tide nears, the water level falls below the level of the sensors which are then exposed to the air for up to 7 hours. During this period of low tide, we expect that suspended sediment levels are low, due to the 'slack' current. As the tide turns, the flood waters submerge the sensors. The flood tide is already running fairly quickly, and OBS levels are high. As slack high tide is approached, the current weakens and OBS levels fall.

The high suspended sediment levels occur during the strong ebb/flood currents associated with the lowest of the low tides. Sediment re-suspension occurs when the current speed (as measured by the sensor $80 \mathrm{~cm}$ above bottom) reaches about $30-40 \mathrm{~cm} \mathrm{~s}^{-1}$. This is consistent with a $25 \mathrm{~cm}$ $\mathrm{s}^{-1}$ threshold current for re-suspension of fine sand $(0.125 \mathrm{~mm})$, based on the Hjulstrom Curves.

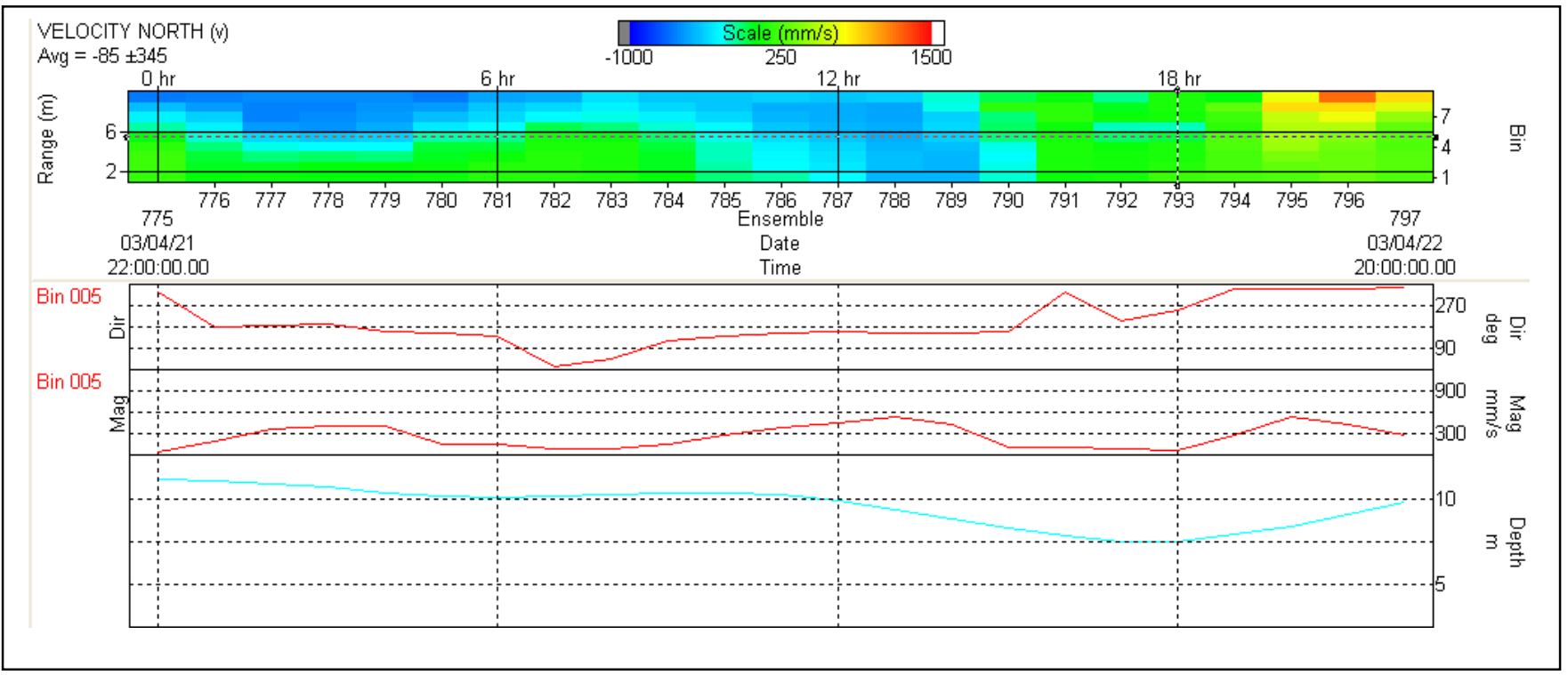

Fig. 10. ADCP current profile data for April 22, 2003 (north component of velocity is in $\mathrm{mm} \mathrm{s}^{-1}$ ). The speed direction time series for a mid-depth is shown in the lower portion, along with the pressure time series. 


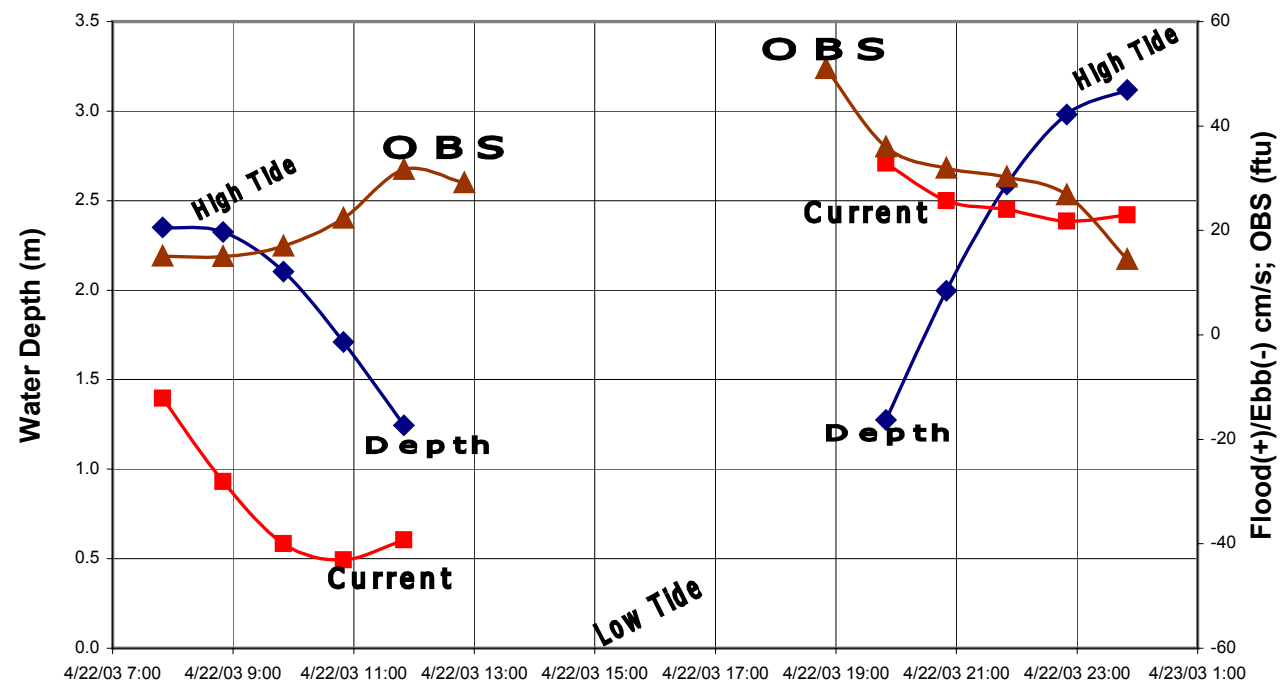

Fig. 11. Norton sensor data during the lower low tide of April 22, 2003.

\section{SUMMARY/CONCLUSIONS}

Norton has proven to be a versatile and effective tool for the study of sediment transport and other near-bottom processes. It is easily configurable to match the specific needs of any given study. The lightweight and collapsible tripod allows it to be transported in a pickup truck and easily deployed from most vessels.

The first two deployments of Norton have provided the following insights into improved deployment methodology:

- Sonar images of small ripple-like bedforms can be difficult to interpret. The irregularity of the ripplefeatures complicates the sonar image. Also, the acoustic returns arrive from varying angles off the ripple faces, backs and ends as the sonar head rotates $360^{\circ}$. It is now thought that it is better to collect a 'burst' of about five images and average them together. This will be incorporated in the next study.

- It is beneficial to visually inspect the bedforms at some time during the deployment. This provides a benchmark and greatly assists with the interpretation of the sonar images. While this is more difficult in situations where the instrumentation is always immersed, the use of underwater video cameras may permit this observation.

We have added the Imagenex pencil beam sonar to our wish list of mounted instruments. This sonar provides a linear cross-section profile of the bedforms, allowing better estimation of the height and wavelength.

\section{ACKNOWLEDGMENTS}

- Within ASL: Dave English - fabrication, field work; Matt Tradewell - instrument set-up and field work; Vincent Lee - data processing.

- Gwyn Lintern (U. Victoria Post Doctoral Fellow) - assistance during deployment and recovery.

- Captain/crew of the Canadian Coast Guard Hovercraft Siyay.

- Comments from an anonymous Geological Survey of Canada reviewer. 


\section{REFERENCES}

[1] D. Heffler, 1996. RALPH - A Dynamic Instrument for Sediment Dynamics. Proceedings Oceans'96, 5 $\mathrm{p}$.

[2] M.Z. Li and C.L. Amos, 1997. Field observations of sheet flow and large wave ripples under combined waves and currents. Proceedings Canadian Coastal Conference 1997.

[3] P.R. Hill and S.H. Davidson, 2002. Preliminary modeling of sediment transport on the upper foreslope of the Fraser River Delta. Geol. Survey Canada, Curr. Res. 2002-E2, 9 p.

[4] J.V. Barrie and R.G. Currie, 2000. Human impact on the sedimentary regime of the Fraser River Delta, Canada, J. Coastal Res. 16(3) pp. 747-755.

[5] P. McLaren and P. Ren, 1995. Sediment transport and its environmental implications in the lower Fraser River and Fraser Delta. GeoSea Consulting (Canada) Ltd., Salt Spring Island, B.C. Further information available from Environment Canada in FRAP Report 1995-03.

[6] Fisheries and Oceans Canada, 1983. Current Atlas; Juan de Fuca to Strait of Georgia. Can. Hydr. Serv., $212 \mathrm{p}$.

[7] R. Thomson, 1981. Oceanography of the British Columbia Coast, Can. Spec. Publ. Fish. Aquat. Sci. 56: $291 \mathrm{p}$.

[8] P.R. Hill, S. Meule, L. Carle, S.H. Davidson and J.V. Barrie, 2002. Detailed morphology and sediment transport processes in the nearshore of the Fraser River Delta, British Columbia. Proceedings American Geophysical Union 2002 Fall Meeting, San Francisco, California, 6-10 December 2002.

Geological Survey of Canada Publication No. 2003086 